Meta

Journal des traducteurs

Translators' Journal

\title{
La traducción del cuento literario costarricense en Estados Unidos: producción, selección e imagen
}

\section{Francisco Javier Vargas Gómez}

Volume 63, numéro 2, août 2018

URI : https://id.erudit.org/iderudit/1055143ar

DOI : https://doi.org/10.7202/1055143ar

Aller au sommaire du numéro

Éditeur(s)

Les Presses de l’Université de Montréal

ISSN

0026-0452 (imprimé)

1492-1421 (numérique)

Découvrir la revue

Citer cet article

Vargas Gómez, F. J. (2018). La traducción del cuento literario costarricense en Estados Unidos: producción, selección e imagen. Meta, 63(2), 342-364. https://doi.org/10.7202/1055143ar
Résumé de l'article

Nous présentons ici les résultats d'une étude sur la traduction du récit littéraire du Costa Rica. Nous avons adopté une approche sociologique (Thompson 1990) et analysé seize anthologies avec des traductions en anglais (des récits littéraires du Costa Rica) publiées aux États-Unis au cours de la seconde moitié $\mathrm{du} \mathrm{XX}{ }^{\mathrm{e}}$ siècle. Notre objectif était d'identifier 1 ) les principes qui gouvernent la production de ces anthologies et 2) l'image qu'ils projettent de la littérature du Costa Rica, mais surtout de révéler les mécanismes qui motivent la traduction des littératures périphériques et leur apparence dans des environnements hégémoniques du point de vue linguistique et littéraire. À la suite d'une analyse contextuelle, socio-situationnelle et paratextuelle du corpus, il est possible de conclure que la traduction des littératures périphériques est une activité secondaire et instrumentale qui n'a pas de capacité apparente de fixer ses propres objectifs et qui est au service d'autres activités et systèmes (primaires) qui la contrôlent. 


\title{
La traducción del cuento literario costarricense en Estados Unidos: producción, selección e imagen
}

\author{
FRANCISCO JAVIER VARGAS GÓMEZ \\ Universidad Nacional, Heredia, Costa Rica \\ vargasgomezfrancisco@gmail.com
}

\section{RÉSUMÉ}

Nous présentons ici les résultats d'une étude sur la traduction du récit littéraire du Costa Rica. Nous avons adopté une approche sociologique (Thompson 1990) et analysé seize anthologies avec des traductions en anglais (des récits littéraires du Costa Rica) publiées aux États-Unis au cours de la seconde moitié du XXe siècle. Notre objectif était d'identifier 1 ) les principes qui gouvernent la production de ces anthologies et 2) l'image qu'ils projettent de la littérature du Costa Rica, mais surtout de révéler les mécanismes qui motivent la traduction des littératures périphériques et leur apparence dans des environnements hégémoniques du point de vue linguistique et littéraire. À la suite d'une analyse contextuelle, socio-situationnelle et paratextuelle du corpus, il est possible de conclure que la traduction des littératures périphériques est une activité secondaire et instrumentale qui n'a pas de capacité apparente de fixer ses propres objectifs et qui est au service d'autres activités et systèmes (primaires) qui la contrôlent.

\section{ABSTRACT}

The results of a research project on the translation of the Costa Rican short story are presented. Sixteen translation anthologies with translations of Costa Rican short stories, published in the United States during the second half of the 20th century, were analyzed from a sociological perspective (Thompson 1990). The objective was to determine the forces behind their production as well as the image they portray of the source literature and, in the process, shed some light on the mechanics governing the translation of minority literatures and their emergence in linguistic and literary hegemonic contexts. After contrasting the contextual, sociosituational, and paratextual realities of the sixteen anthologies, it is possible to conclude that the translation of minority literatures is a subsidiary and instrumental activity with no apparent capacity to set its own goals and is at the service of primary activities and systems that rule over it.

\section{RESUMEN}

Se presentan los resultados de un proyecto de investigación sobre la traducción del cuento literario costarricense. Se adopta un enfoque sociológico (Thompson 1990) para analizar un conjunto de dieciséis antologías de traducción, publicadas en los Estados Unidos durante la segunda mitad del siglo xx y en las que se incluyeron traducciones de cuentos literarios costarricenses. El estudio tenía como objetivo identificar 1) los principios que regularon la producción de aquellas antologías y 2) la imagen que proyectan de la literatura de Costa Rica. El fin último: desvelar en lo posible la mecánica que rige la traducción de literaturas periféricas y su aparición en entornos lingüísticos y literarios hegemónicos. Tras describir y contraponer las realidades contextuales, socio-situacionales y paratextuales del corpus, es posible concluir que la traducción de literaturas periféricas es una actividad y un sistema de carácter subsidiario e instrumental, sin capacidad aparente para establecer sus propios objetivos y al servicio de otras actividades y sistemas (primarios) que la condicionan. 


\section{MOTS-CLÉS/KEYWORDS/PALABRAS CLAVE}

littératures périphériques, récits littéraires, traduction, Costa Rica, anthologies minority literatures, short story, translation, Costa Rica, anthologies literaturas periféricas, cuento literario, traducción, Costa Rica, antologías

\section{Introducción}

En el presente artículo se resumen y discuten los resultados de una investigación que se inscribe, en términos generales, dentro del campo de la traducción literaria y que se abocó, en términos concretos, a estudiar la mecánica que rige la traducción de literaturas periféricas hacia entornos lingüísticos que podrían denominarse hegemónicos ${ }^{1}$. Para ello se abordó el caso de la traducción de la literatura costarricense en tanto literatura periférica. Específicamente, se analizó una serie de publicaciones de carácter antológico que surgieron en los Estados Unidos durante la segunda mitad del siglo pasado y en las que se incluyeron traducciones al inglés de cuentos literarios costarricenses.

El estudio de la traducción de literaturas periféricas no es un asunto del todo nuevo. Desde una óptica sobre todo europea, por ejemplo, son varios los trabajos que se han ocupado del tema: Sampson (2004) estudia el caso de la traducción de literatura eslovaca al inglés en el Reino Unido; Kamenish y Zabic (2006) abordan la traducción de poesía bosnia, croata y serbia en Estados Unidos y Canadá; por su parte, Linn (2006) se ocupa de la literatura holandesa y su traducción al español; la traducción al francés de literatura producida en Europa del este (Polonia, Checoslovaquia, Hungría y Rumanía) durante el periodo comunista es el principal interés de Popa (2006); por último, Ozbot (2011) centra su atención en la traducción de literatura eslovena en Italia.

Asimismo, se han hecho esfuerzos por ahondar en una realidad mucho más cercana a la que se estudia en estas páginas: la traducción de literatura latinoamericana. Tales estudios parecen coincidir, desde sus perspectivas particulares, al menos en dos ideas principales: primero, que la traducción de las literaturas latinoamericanas, en tanto periféricas, parece siempre adecuarse y depender del polo de recepción (en lo que respecta a qué, cuánto, cuándo y cómo se traduce) y, segundo, que los procesos de traducción en tales casos terminan por generar imágenes cuando menos parcializadas del entorno y de la literatura de partida. Tales ideas se desprendían ya del estudio que Siebenmann realizará en 1991 sobre la traducción de literatura latinoamericana en diferentes espacios de habla alemana durante ciertos momentos del siglo pasado. El análisis que Alvstad (2012) practica sobre un conjunto de antologías de traducción de literatura latinoamericana al sueco también pone de manifiesto la forma en que el proceso de traducción puede llegar a provocar una reconfiguración o representación parcial tanto de la literatura como del polo de partida. Galvin (2014) hace lo propio al demostrar cómo, con el objetivo de renovar la poética del polo de recepción, se manipula el original para presentar al lector meta un texto y un escritor diferentes a los originales. Vargas Gómez (2012) añade que ya el propio proceso de selección de aquello que se traduce implica generar una visión sesgada del entorno poético-literario de partida.

Bielsa (2013), por su parte, a partir del caso de la traducción de la obra de Roberto Bolaño, expone la manera en que la consagración de literaturas y autores periféricos 
se ve condicionada por los flujos de traducción hacia espacios y lenguas hegemónicas. Vargas Gómez $(2012,2015)$ estudia el caso de la traducción de la poesía costarricense y ahonda de manera similar en la dependencia y adecuación de los procesos de traducción de literaturas periféricas a las tendencias poético-literarias propias del polo de recepción; concluye que la aparición de una traducción que involucre a una literatura periférica depende de la coincidencia y armonía de diferentes factores histórico-contextuales, socio-situacionales y poético-literarios. Finalmente, Franco Aixelá y Vargas Gómez (2012) plantean que en general, pero sobre todo en el caso de las literaturas periféricas, la traducción no es un instrumento democrático ni un puente cultural, sino un embudo que favorece la traducción de ciertas literaturas mientras perpetúa los desequilibrios y las imágenes predeterminadas.

En cuanto a las antologías de traducción, son varios los estudios que señalan las ventajas de recurrir a ellas como medio para estudiar la mecánica que gobierna el fenómeno en general. En determinados casos se destaca la función de las antologías de traducción, no solo como canal de difusión de la producción literaria de diferentes entornos, sino también como participantes activos en las transformaciones internas de los sistemas literarios a los que se incorporan (Göske 1990: 35-36; Enríquez Aranda 2004: 63). Hasta cierto punto, también se les valora como elementos estructuradores del medio cultural de recepción (Essmann y Frank 1991: 66, 68).

Odber de Baubeta (2012: 71) sugiere que el análisis de la relación entre la producción de antologías y la traducción constituye por sí mismo una rama de los Estudios de Traducción que ha contado desde hace algún tiempo con seguidores destacados: el grupo de Göttingen en Alemania, Anthony Pym (también relacionado en algún momento con la Universidad de Göttingen) y los participantes de la 6th Conference on Translation Studies in Portugal, International Conference on Translation in 19th- and 20th-century Anthologies and Collections, que tuvo lugar en mayo de 2010. Al referirse a la relación entre la rama descriptivista de los Estudios de Traducción y lo que denomina «Descriptive Anthology Studies», Odber de Baubeta indica que «the history of anthologies is inextricably bound up with the history of translation, since so many anthologies depend for their contents on translations of poems, short stories, scenes from plays, or excerpts from essays» (2012: 71-72). De seguido destaca la función que han tenido las antologías de traducción para entronar a ciertos autores, cuyas obras se traducen de manera recurrente, así como la idea de que son un elemento central en la comprensión de los procesos históricos de recepción y publicación (de Baubeta 2012: 72-73). Las antologías de traducción, concluye el autor, representan un medio ideal para abordar todo tipo de problemas desde diversas perspectivas (lingüística, feminista, posestructuralista, histórica y sociocultural, entre otras).

Por otra parte, también se ha señalado la utilidad del estudio de las antologías de traducción como medio para revelar aspectos propios del polo de recepción. Lieven D'hulst (1995: 12) se adelantaba en su momento y apuntaba que por medio del estudio de las antologías de traducción se podrían plantear respuestas preliminares a algunas de las más complejas preguntas sobre los comportamientos que subyacen en la cultura meta. Gallego Roca parece destacar el mismo potencial revelador de las antologías de traducción en cuanto al polo de recepción al afirmar que «las traducciones y las antologías [...] son pequeñas enciclopedias que evidencian los modelos que conviven y luchan en el seno de un sistema literario» (1994: 249), sistema al cual 
se incorporan las traducciones y dentro del cual se fijan de previo los criterios de selección de aquello que posteriormente se incorporará en forma de traducción. Por su parte, pero siempre en la misma línea, Mercedes Enríquez Aranda (2004: 63-64) propone que profundizar en el estudio de las antologías de traducción es ahondar al mismo tiempo en la función que cumplen dentro del polo de recepción, así como en los mecanismos que rigen los procesos que conducen a su incorporación a tal polo.

De manera complementaria, se ha postulado que el análisis de las antologías de traducción posibilita el estudio de la manera en que se construye la imagen del polo de partida y de su literatura dentro del polo de recepción. Así parece entenderlo Alvstad tras estudiar nueve antologías/traducciones de literatura latinoamericana publicadas en Suecia entre 1954 y 1998:

$[\mathrm{T}]$ ranslation anthologies produce not only images and ideas of literary works and authors, but also a re-imagining of the region as a whole [...] Anthologies are a privileged locus for studying a target culture's construction of a specific source culture and literature [and] may influence the future reception of a specific kind of literature, even when print runs are small in terms of number. The overviews provided in them are likely to guide readers to other translations from the same area (Alvstad 2012: 42-43).

Así, al interpretarse dentro del polo de recepción como una muestra de la producción literaria del polo de partida, las antologías de traducción inevitablemente inciden en la manera en que el lector meta percibe tanto la literatura de partida como el entorno sociocultural e histórico en que se originó. El resultado será siempre una imagen irremediablemente sesgada del entorno de partida que se forma a partir de los intereses del contexto meta: «[t]oda traducción supone una interpretación, y toda selección, una forma de apropiarse de una obra ajena para hacerla funcionar de un modo específico» (Gallego Roca 1994: 253).

Resulta claro que los atributos de las antologías de traducción las posicionan como un objeto de particular interés para abordar el fenómeno de la traducción, sobre todo en lo que concierne a los mecanismos que regulan los procesos de selección, producción, flujo y recepción, así como a la función que pueden llegar a desempeñar dentro de los entornos en que se inserten. Es quizás por tales razones que Enríquez Aranda sostiene que «[l]a traductología descriptiva [...] es una de las áreas dentro de los estudios de traducción que más provecho puede sacar de la investigación de las antologías de traducción» (Enríquez Aranda 2004: 63).

Retomando ahora el asunto de la traducción del cuento literario costarricense, son tres las situaciones que despertaron el interés sobre el tema. La primera corresponde a la posición particularmente periférica que ocupa la producción literaria de Costa Rica. Se puede afirmar que en términos históricos y a pesar de haber proliferado dentro de las fronteras nacionales por más de un siglo, lo cierto es que la literatura costarricense ocupa un lugar bastante periférico en la palestra internacional, incluso si se le compara con otras tradiciones literarias centro e hispanoamericanas o del Caribe ${ }^{2}$. Tal situación podría deberse a la relativa falta de «atractivo» general que históricamente ha tenido el país, sobre todo en ciertos periodos del siglo pasado en comparación, por ejemplo, con algunas de las restantes naciones centroamericanas (en su momento más llamativas en el ámbito internacional, en parte a causa de los conflictos armados, políticos y migratorios surgidos en países como Panamá, Nicaragua, El Salvador o Guatemala). Por otro lado, tampoco han surgido en Costa Rica autores que hayan alcanzado amplio reconocimiento fuera del espacio local (un 
Darío, un Asturias, un Moterroso, un Sergio Ramírez, un Ernesto Cardenal o una Gioconda Belli) que posicionaran a su literatura en las primeras planas extranjeras. Aunque no necesariamente las únicas, por sí solas aquellas circunstancias habrían restado visibilidad a las letras de Costa Rica, propiciando a la vez que ocupasen una posición bastante periférica comparativamente hablando y un menor volumen de traducción de sus obras en términos relativos. Tales particularidades hacen de la aparición de un conjunto de traducciones de obras costarricenses en un momento y espacio dados un hecho como mínimo curioso que merece ser estudiado.

La segunda tenía que ver con la cuestión de aquello o más bien aquellos que fueron traducidos. Si bien en términos relativos la rama narrativa de la literatura en Costa Rica no ha sido escasa ni en sus exponentes ni en sus productos, cuando hablamos de su traducción el panorama es distinto. De la misma manera que ha sucedido con la poesía (Vargas Gómez 2012), lo cierto es que han sido comparativamente pocos los escritores de cuento literario costarricense que se han traducido. Al respecto, parece propicio mencionar ahora que de un total de 130 narradores tomados en cuenta, solamente 55 habían sido traducidos, varios de ellos en más de una ocasión y únicamente 30 aparecieron representados en las antologías examinadas. ¿Qué ha regido entonces la selección de escritores por traducir? Por otro lado, ¿qué imagen proyectan las traducciones realizadas a partir de tal selección?

La tercera situación se relacionaba más bien con la existencia misma de las traducciones. Dejando de lado el factor cuantitativo, no puede pasarse por alto el hecho de que la literatura costarricense ha sido, es y posiblemente seguirá siendo -al menos en un futuro cercano- una literatura muy periférica dentro del ámbito estadounidense $e^{3}$. Así pues, aunque 90 cuentos traducidos (incluidos en las antologías analizadas) parecen ser una cifra bastante modesta, no deja de ser llamativa su aparición dentro de un entorno estadounidense que en términos literarios puede considerarse como hegemónico y autosuficiente y, en todo caso, cuyos intereses a lo externo se han fijado tradicionalmente en literaturas más visibles desde su óptica (la mexicana, la suramericana, la rusa y la europea, entre otras). ¿Qué la ha propiciado entonces?

Así las cosas, el objetivo que se perseguía no era otro más que identificar los principios que regularon los procesos de producción y selección asociados a las traducciones de cuento literario costarricense antes referidas así como delimitar la imagen que proyectan de la literatura de origen. Bajo tal planteamiento y por extensión, se ha pretendido también generar un aporte, desde un caso específico más, al conjunto de conocimientos que a la fecha se han acumulado en torno al funcionamiento de las fuerzas que rigen la traducción de literaturas periféricas y su aparición en entornos lingüísticos dominantes.

\section{Los presupuestos teóricos}

La adopción de los postulados del sociólogo John B. Thompson (1990) sobre las formas simbólicas permite observar aspectos paratextuales concretos, presentes en un conjunto de publicaciones resultantes de la actividad traductora, para luego asociarlos con sus entornos de producción. Como se verá a continuación, el énfasis en las formas simbólicas y la manera en que clasifica sus distintas dimensiones $-\mathrm{y}$ por extensión las de la traducción- posibilita operacionalizar detalladamente el fenómeno por estudiar y sus productos, lo cual facilitó, a su vez, el escrutinio de las antologías. 
En este sentido, la vía que ofrece Thompson ha parecido en este caso más adecuada que otros enfoques sociológicos aplicados al estudio de la traducción (basados principalmente en la obra de Pierre Bourdieu 1977; 1991), los cuales suelen poner el énfasis en los entornos, en los agentes, en sus relaciones y, en especial, en el traductor en tanto individuo y profesional (Pym 2006; Wolf y Fukari 2007).

Para Thompson, una forma simbólica es un hecho cultural que se produce en situaciones socialmente estructuradas, tales como gestos, rituales, afirmaciones, programas de televisión, obras de arte y textos, entre otros. Indica además que tales formas se encuentran inmersas tanto en contextos sociohistóricos como en procesos a partir y dentro de los cuales se determina la manera en que se producen, transmiten y reciben (Thompson 1990: 136-138).

Advierte Thompson (1990: 137-146) que se pueden distinguir cinco diferentes dimensiones en una forma simbólica, mismas que se definen a continuación:

1) Dimensión intencional: alude al hecho de que toda forma simbólica es siempre el resultado de las acciones de un productor que a la vez tiene, también siempre, a un usuario meta en mente al momento de la producción.

2) Dimensión convencional: implica que todo proceso de producción de una forma simbólica dada se adecua a patrones específicos de producción y configuración que son culturalmente condicionados a partir del contexto en que se utilice.

3) Dimensión estructural: sugiere que toda forma simbólica se estructura de manera tal que sus elementos constituyentes se organizan y relacionan en formas específicas que se encuentran en consonancia con sus dimensiones intencional, convencional y contextual.

4) Dimensión referencial: refiere al hecho de que cada forma simbólica no solo representa a un referente determinado, sino que además dice algo sobre el referente representado.

5) Dimensión contextual: apunta a que la producción y recepción de toda forma simbólica tiene siempre lugar dentro de momentos y espacios específicos a los que se adecua en unas u otras maneras.

\subsection{La producción de las formas simbólicas}

Tal fragmentación implica que en toda situación de producción de formas simbólicas habría tres realidades fundamentales: la realidad sociohistórica (que moldearía las dimensiones convencional y contextual), la realidad socio-situacional (que da cuenta de la dimensión intencional o situación de producción) y la realidad producida o el producto en sí mismo (que devela y constituye las dimensiones estructural y referencial de las formas simbólicas).

Cabe destacar que esta última (la realidad producida) será una variable dependiente en su configuración de las dos anteriores (Vargas Gómez 2012: 109). Por su parte, la realidad socio-situacional estará conformada por diferentes actores que interactúan entre sí en una situación de producción que toma lugar dentro de una realidad sociohistórica específica con la cual también interactúan. Se debe señalar que tales interacciones se caracterizan por las asimetrías entre actores, lo cual implica que habrá necesariamente actores con mayor acceso a determinados recursos y oportunidades (Thompson 1990: 136, 150-151).

Dicho esto, se esperaría que mientras unos actores protagonizan los procesos de producción de formas simbólicas, otros tendrán solamente un papel secundario o 
subordinado, lo cual supone a su vez que ciertos actores imponen -de manera consciente o inconsciente- sus intereses sobre tales procesos. En consecuencia y dada su dimensión referencial, las formas simbólicas necesariamente tenderán a responder y reflejar de manera directa los intereses de quienes protagonicen sus procesos de producción y, de forma indirecta, los de las realidades situacional y sociohistórica en y con las que interactúan tales actores.

\subsection{Los principios que rigen la producción de las formas simbólicas}

A partir de las ideas anteriores ha sido posible postular una serie de principios que vendrían a regular la producción de las formas simbólicas y, por extensión, de las traducciones. Tales principios ya se han demarcado en otro momento, pero se repasan a continuación con el fin de evidenciar los presupuestos de los cuales se parte para generar secciones posteriores:

1) La producción de formas simbólicas responde, por una parte, a los intereses, necesidades, propósitos, oportunidades y recursos de sus productores y usuarios específicos.

2) Por otra parte, responde a la vez a las carencias o demandas de los entornos sociohistóricos específicos en que se producen [o utilizan].

3) No todos los factores que intervienen en su producción -ya sean sociohistóricos o socio-situacionales- poseen el mismo peso, ni sobre los procesos que conducen a su producción ni sobre la configuración específica que adquieran.

4) La posición social [o hegemonía] de los productores así como su acceso a determinadas oportunidades y recursos posibilita la producción de formas simbólicas específicas y refrena la aparición de otras.

5) De igual manera, el valor que pueda despertar cierta forma simbólica en sus productores o receptores [y en los entornos en que se producen o a los que van dirigidas] frente a otras determinará las probabilidades de que se asuma su producción (Thompson 1990: 154).

6) Su configuración interna [textual y paratextual ${ }^{4}$ en el caso de la traducción de textos escritos] será coherente con las circunstancias, intereses, necesidades, propósitos, oportunidades y recursos detrás de su producción.

7) Dicha configuración tomará como punto de partida reglas de naturaleza convencional propias del contexto sociohistórico en que se producen [o utilicen]; convenciones que dictan lo que deberían ser o no ser en tanto cobran significado a partir de un conjunto de formas similares precedentes. (Vargas Gómez 2012: 110)

\section{Metodología}

El trabajo de análisis consistió en la contraposición de las distintas realidades que constituyen la situación de producción del corpus examinado. Tal contraposición se llevó a cabo con el fin de establecer relaciones entre dichas realidades (a partir de las cuales derivar los principios específicos que rigieron la producción de las 16 antologías observadas) y se llevó a cabo en dos fases: una primera, de carácter más bien descriptivo, que implicó la recopilación del corpus de trabajo, la extracción de datos, su posterior formalización y la demarcación de patrones o perfiles por medio de los cuales describir las distintas realidades del corpus así como la imagen que llegó a proyectar. En una segunda fase, de tipo explicativa, se interpretaron los resultados obtenidos en la fase anterior y se indujeron una serie de principios que habrían 
regulado los procesos de producción y selección relacionados con los volúmenes que se analizaron.

\subsection{El corpus de trabajo}

Como ya se ha mencionado, el corpus de antologías estudiado estuvo constituido por 16 volúmenes publicados en suelo estadounidense en los que se incluyeron traducciones al inglés de cuento literario costarricense. Dicho número correspondió al 94\% del universo conocido al momento de realizar el estudio, lo cual le confiere una alta representatividad para el caso. Del conjunto total, 15 antologías se publicaron en formato monolingüe y una sola en un formato parcialmente bilingüe; únicamente tres de ellas fueron dedicadas a la literatura de Costa Rica en exclusiva. El espectro temporal de publicación iba de 1975 a 2010, a razón de 2 durante las décadas de 1960 y 1970, 7 entre 1980 y 1991, y las 7 restantes a partir de $1991^{5}$.

El corpus de antologías recién descrito fue ubicado a partir de una revisión de la producción literaria de los narradores costarricenses publicada durante el siglo pasado, en otras palabras, a partir de los originales. Esto implicó, en primera instancia, la conformación de una lista que incluyó a todos los escritores costarricenses de narrativa que hubiesen publicado durante el siglo xx. El resultado de tal proceso fue un conjunto de 130 nombres. A partir de tal lista se llevó a cabo un proceso de búsqueda, escritor por escritor, en catálogos bibliográficos ampliamente reconocidos y pertinentes para el caso (Library of Congress y OCLC WorldCat, por ejemplo). Dicho proceso resultó a su vez en la configuración de un listado que incluía las 16 referencias bibliográficas de las obras que llegarían a constituir el corpus de trabajo. Por último, se procedió a recopilar los volúmenes publicados en formato impreso.

\subsection{Los aspectos estudiados}

Siendo la traducción una forma simbólica, cabe estudiarla a partir de sus realidades y dimensiones constituyentes según se han demarcado ya (véase $\$ 1$ ). Los presupuestos teóricos). Con esto en mente, se operacionalizó el fenómeno estudiado y se descompuso el concepto traducción en componentes cada vez más concretos, esto a medida que se avanzaba en un sistema de cinco esferas sucesivas: realidades, dimensiones, variables, subvariables e indicadores.

Así, la primera esfera del concepto traducción está constituida por tres realidades: la socio-situacional, la textual y la sociohistórica. Ya en la segunda esfera, la realidad socio-situacional presenta una única dimensión (la intencional), en la cual es posible distinguir dos variables (propias de la tercera esfera): los productores y los receptores. $\mathrm{Al}$ descender a la cuarta esfera, se observa que la variable productores presenta a su vez dos subvariables: los editores (con sus cinco indicadores: espacio de procedencia, ocupación, campo de acción, filiaciones/intereses y posición) y las editoriales (con cinco indicadores también: tipo, espacio de procedencia, campo de acción, compromisos/intereses y posición). La variable receptores, por su parte, cuenta con una única subvariable: el lector meta, cuyos indicadores son el grado de interés, el grado de especialización y el grado de especificidad. Todos los indicadores antes referidos se ubican en la última esfera.

Por su parte, la realidad textual se disloca en dos dimensiones: la estructural y la referencial. En la primera de ellas, la estructural, se identifican dos variables: por 
un lado, el contenido-forma textual (que no se ha tomado en cuenta en este caso ya que el ámbito estrictamente textual, al cual pertenece, no se abordó al realizar el estudio) y, por otro lado, el contenido paratextual, cuya subvariable (los paratextos de cada antología) se estudia por medio de sus indicadores respectivos (año de publicación, espacio de publicación, tipo de antología, propósito y número de sistemas abarcados). La dimensión referencial cuenta con una única variable (la imagen proyectada), cuya subvariable (los cuentos traducidos) se examinaron por medio de sus cuatro indicadores: filiaciones, temporalidad, tipo y temática de la obra.

Para finalizar, son también dos las dimensiones propias de la realidad sociohistórica: la contextual y la convencional. La dimensión contextual cuenta con dos variables: el polo de recepción y el polo de partida (esta última irrelevante en este caso por haber sido todos los componentes del corpus de trabajo producidos dentro del polo de recepción). La variable polo de recepción (sin subvariables identificadas) se estudió por medio de sus cuatro indicadores: tendencias literarias, tendencias políticas, tendencias económicas y tendencias académicas. La dimensión convencional presenta dos variables: los principios traductores (que también se encontraban más allá de los objetivos del estudio) y los principios poético-literarios, para cuya subvariable (los escritores seleccionados) se delimitaron cuatro indicadores: el núcleo generacional, la filiación poética, la filiación estética y la filiación ideológica. En su totalidad, los indicadores señalados para cada una de las tres realidades del fenómeno estudiado, y que a la vez constituyen su esfera más concreta, constituyen el conjunto de aspectos estudiados.

\section{El análisis}

Antes de presentar los resultados del análisis, parece pertinente ilustrar la forma en que se procesó cada una de las antologías que conforman el corpus estudiado a partir de la compartimentación de la realidad esbozada al final del apartado anterior. Con tal fin, se presenta ahora, a manera de ejemplo, el caso de la antología And We Sold the Rain. En dicho caso, al igual que se hiciera con las restantes 15 antologías, se extrajeron datos relativos a sus cinco dimensiones.

\subsection{And We Sold the Rain, ejemplo de antología analizada}

A continuación, se presentan los datos correspondientes a las cinco dimensiones de la antología que sirve como ejemplo. Nótese que en todos los casos en la columna de la izquierda de cada cuadro se consignan los aspectos estudiados y en la de la derecha su caracterización particular.

\subsubsection{And We Sold the Rain, dimension intencional}

TABLA 1

\section{La editora}

\begin{tabular}{|l|l|}
\hline Espacio de procedencia & Polo de recepción \\
\hline Ocupación & Encargada del programa de becas Fulbright para Latinoamérica \\
\hline Campo de acción & Editorial; literario-cultural; intercambios estudiantiles \\
\hline Filiaciones/ Intereses & Literarios y culturales (relacionados con Latinoamérica) \\
\hline Posición & Minoritaria \\
\hline
\end{tabular}


TABLA 2

La editorial

\begin{tabular}{|l|l|}
\hline Casa editorial & Four Walls Eight Windows \\
\hline Tipo de editorial & Independiente \\
\hline Espacio de procedencia & Polo de recepción (Nueva York) \\
\hline Campo de acción & El mercado editorial y literario de tipo independiente \\
\hline Compromisos e intereses & Literarios alternativos y periféricos; políticos de corte progresista \\
\hline Posición & Minoritaria \\
\hline
\end{tabular}

TABLA 3

El lector meta (perfil)

\begin{tabular}{|l|l|}
\hline Grado de interés & $\begin{array}{l}\text { Interesado (en Centroamérica; en la situación y literatura del polo de } \\
\text { partida) }\end{array}$ \\
\hline Grado de especialización & No especializado \\
\hline Grado de especificidad & $\begin{array}{l}\text { Relativamente amplio (de carácter general entre los lectores } \\
\text { interesados) }\end{array}$ \\
\hline
\end{tabular}

\subsubsection{And We Sold the Rain, dimensión convencional}

TABLA 4

\section{Los escritores seleccionados y sus obras (perfil)}

\begin{tabular}{|c|c|}
\hline Núcleo generacional & $\begin{array}{l}\text { - Cuarta promoción (generación del 40; surgen aproximadamente a } \\
\text { partir de 1940) } \\
\text { - Quinta promoción (Segunda República, surgen aproximadamente } \\
\text { a partir de 1960) }\end{array}$ \\
\hline Filiación poética & $\begin{array}{l}\text { - Instrumento de lucha revolucionaria, de concientización y } \\
\text { transformación de la realidad nacional (Quesada Soto 2008: 85). } \\
\text { Reflejo dialéctico y crítico de la realidad objetiva (Quesada Soto } \\
\text { 2008: 85) } \\
\text { - Medio de exploración del espacio subjetivo y de nuevas formas y } \\
\text { contenidos, de reformulación de los modelos estético-literarios } \\
\text { anteriores y de restructuración del orden social }\end{array}$ \\
\hline Filiación estética & $\begin{array}{l}\text { - Lo social, lo agrario, el realismo } \\
\text { - Social-subjetivo, historicismo, literatura fantástica y de intención } \\
\text { lúdica, «vanguardista» (innovadora) }\end{array}$ \\
\hline Filiación ideológica & $\begin{array}{l}\text { - Socialismo, comunismo } \\
\text { - Tendencias sociales }\end{array}$ \\
\hline
\end{tabular}

\subsubsection{And We Sold the Rain, dimensión estructural}

TABLA 5

\section{Perfil a partir del contenido paratextual}

\begin{tabular}{|l|l|}
\hline Año de publicación & 1988 \\
\hline Espacio de publicación & Polo de recepción (Nueva York) \\
\hline Tipo de antología & Crítica (obra literaria) \\
\hline Compromiso & Para con un colectivo (las sociedades centroamericanas) \\
\hline Propósito & $\begin{array}{l}\text { Revolucionar las formas de comportamiento más usuales o las } \\
\text { perspectivas convencionales }\end{array}$ \\
\hline Número de sistemas incluidos & Multilateral (literatura de los países centroamericanos) \\
\hline
\end{tabular}




\subsubsection{And We Sold the Rain, dimensión contextual}

TABLA 6

El polo de recepción

\begin{tabular}{|l|l|}
\hline Tendencias poético-literarias & $\begin{array}{l}\text { - Ruptura, lo étnico, lo minoritario y lo social } \\
\text { - Resurgimiento del interés por lo tradicional }\end{array}$ \\
\hline Tendencias políticas & $\begin{array}{l}\text { - Lo minoritario } \\
\text { - Sociedad altamente politizada } \\
\text { - Conservadurismo } \\
\text { - Intereses ideológico-políticos sobre el polo de partida }\end{array}$ \\
\hline Tendencias económicas & Condicionadas al ámbito político \\
\hline Tendencias académicas & $\begin{array}{l}\text { Consolidación del feminismo y de los estudios de la mujer } \\
\text { dentro del ámbito universitario }\end{array}$ \\
\hline
\end{tabular}

\subsubsection{And We Sold the Rain, dimensión referencial}

TABLA 7

\section{La imagen proyectada}

\begin{tabular}{|l|l|}
\hline Filiaciones & Tradición literaria asociada (a la literatura centroamericana) \\
\hline Temporalidad & $\begin{array}{l}\text { Literatura contemporánea (producida durante la segunda } \\
\text { mitad del siglo xx) }\end{array}$ \\
\hline Tipo & Literatura social \\
\hline Temática & Lo social, lo económico, lo cultural, lo psicológico, lo cotidiano \\
\hline Imagen de la literatura traducida & $\begin{array}{l}\text { Literatura centroamericana contemporánea de tendencias } \\
\text { sociales, que refleja la situación social de los polos de partida }\end{array}$ \\
\hline
\end{tabular}

\subsection{La formalización de los datos: las 16 antologías}

Una vez que las 16 antologías pasaron por el mismo proceso que se ha ilustrado en el epígrafe anterior, se conjuntaron los datos de cada volumen, también por medio de una serie de instrumentos o tablas generales. Esto con el propósito de contraponer las realidades individuales y extraer, mediante la comparación y el contraste, patrones que describiesen la realidad observada.

Las tablas 8 y 9 (a continuación) ilustran los resultantes del proceso recién referido. En este caso se presentan las tablas generales mediante las cuales se perfilaron la dimensión convencional y la dimensión estructural/paratextual del corpus estudiado.

TABLA 8

Formalización de los datos correspondientes a la dimensión convencional del corpus: los escritores seleccionados

\begin{tabular}{|c|c|c|c|c|c|}
\hline & A & B & $\mathrm{C}$ & $\mathrm{D}$ & E \\
\hline & Escritor & Filiación poética & $\begin{array}{l}\text { Filiación } \\
\text { estética }\end{array}$ & $\begin{array}{l}\text { Filiación } \\
\text { ideológica }\end{array}$ & $\begin{array}{c}\text { Núcleo } \\
\text { generacio- } \\
\text { nal }\end{array}$ \\
\hline 1 & $\begin{array}{l}\text { Manuel González } \\
\text { Zeledón }\end{array}$ & $\begin{array}{l}\text { Construcción } \\
\text { de una identidad nacional... }\end{array}$ & Costumbrismo & $\begin{array}{l}\text { Liberalismo, } \\
\text { positivismo... }\end{array}$ & $\begin{array}{l}\text { Primera } \\
\text { promoción }\end{array}$ \\
\hline 2 & Carmen Lyra & $\begin{array}{l}\text { Construcción } \\
\text { de modelos de realidad... }\end{array}$ & $\begin{array}{l}\text { Naturalismo, } \\
\text { realismo... }\end{array}$ & $\begin{array}{l}\text { Decadentismo, } \\
\text { idealismo... }\end{array}$ & $\begin{array}{l}\text { Segunda } \\
\text { promoción }\end{array}$ \\
\hline 3 & $\begin{array}{l}\text { Mario González } \\
\text { Feo }\end{array}$ & $\begin{array}{l}\text { Construcción de modelos de } \\
\text { realidad... }\end{array}$ & $\begin{array}{l}\text { Naturalismo, } \\
\text { realismo... }\end{array}$ & $\begin{array}{l}\text { Decadentismo, } \\
\text { idealismo... }\end{array}$ & $\begin{array}{l}\text { Segunda } \\
\text { promoción }\end{array}$ \\
\hline 4 & $\begin{array}{l}\text { Carlos Salazar } \\
\text { Herrera }\end{array}$ & $\begin{array}{l}\text { Cuestionamiento y } \\
\text { ruptura... }\end{array}$ & $\begin{array}{l}\text { Mezcla de } \\
\text { realismo... }\end{array}$ & $\begin{array}{l}\text { Pragmatismo } \\
\text { industrial... }\end{array}$ & $\begin{array}{l}\text { Tercera } \\
\text { promoción }\end{array}$ \\
\hline
\end{tabular}




\begin{tabular}{|c|c|c|c|c|c|}
\hline 5 & Max Jiménez & $\begin{array}{l}\text { Cuestionamiento } \\
\text { y ruptura... }\end{array}$ & Vanguardismo & $\begin{array}{l}\text { Pragmatismo } \\
\text { industrial... }\end{array}$ & $\begin{array}{l}\text { Tercera } \\
\text { promoción }\end{array}$ \\
\hline 6 & Fabián Dobles & $\begin{array}{l}\text { Lucha revolucionaria, } \\
\text { concientización... }\end{array}$ & $\begin{array}{l}\text { Lo social, } \\
\text { lo agrario... }\end{array}$ & $\begin{array}{l}\text { Socialismo, } \\
\text { comunismo }\end{array}$ & $\begin{array}{l}\text { Cuarta } \\
\text { promoción }\end{array}$ \\
\hline 7 & Carlos Luis Fallas & $\begin{array}{l}\text { ucha revolucionaria, } \\
\text { concientización... }\end{array}$ & $\begin{array}{l}\text { Lo social, } \\
\text { lo agrario... }\end{array}$ & $\begin{array}{l}\text { Socialismo, } \\
\text { comunismo }\end{array}$ & $\begin{array}{l}\text { Cuarta } \\
\text { promoción }\end{array}$ \\
\hline 8 & Joaquín Gutiérrez & $\begin{array}{l}\text { Exploración, descubri- } \\
\text { miento... }\end{array}$ & Lo psicológico... & $\begin{array}{l}\text { Socialismo, } \\
\text { comunismo }\end{array}$ & $\begin{array}{l}\text { Cuarta } \\
\text { promoción }\end{array}$ \\
\hline 9 & Eunice Odio & $\begin{array}{l}\text { Exploración, descubri- } \\
\text { miento... }\end{array}$ & Lo psicológico... & Individualismo & $\begin{array}{l}\text { Cuarta } \\
\text { promoción }\end{array}$ \\
\hline 10 & $\begin{array}{l}\text { Yolanda } \\
\text { Oreamuno }\end{array}$ & $\begin{array}{l}\text { Exploración, descubri- } \\
\text { miento... }\end{array}$ & Lo psicológico... & Individualismo & $\begin{array}{l}\text { Cuarta } \\
\text { promoción }\end{array}$ \\
\hline 11 & Victoria Urbano & $\begin{array}{l}\text { Exploración } \\
\text { del espacio subjetivo... }\end{array}$ & $\begin{array}{l}\text { Social- } \\
\text { subjetivo... }\end{array}$ & $\begin{array}{l}\text { Tendencia } \\
\text { social }\end{array}$ & $\begin{array}{l}\text { Quinta } \\
\text { promoción }\end{array}$ \\
\hline 12 & Samuel Rovinski & $\begin{array}{l}\text { Exploración } \\
\text { del espacio subjetivo... }\end{array}$ & $\begin{array}{l}\text { Social- } \\
\text { subjetivo... }\end{array}$ & $\begin{array}{l}\text { Tendencia } \\
\text { social }\end{array}$ & $\begin{array}{l}\text { Quinta } \\
\text { promoción }\end{array}$ \\
\hline 13 & Delfina Collado & $\begin{array}{l}\text { Exploración } \\
\text { del espacio subjetivo... }\end{array}$ & $\begin{array}{l}\text { Social- } \\
\text { subjetivo... }\end{array}$ & $\begin{array}{l}\text { Tendencia } \\
\text { social }\end{array}$ & $\begin{array}{l}\text { Quinta } \\
\text { promoción }\end{array}$ \\
\hline 14 & Julieta Pinto & $\begin{array}{l}\text { Exploración } \\
\text { del espacio subjetivo... }\end{array}$ & $\begin{array}{l}\text { Social- } \\
\text { subjetivo... }\end{array}$ & $\begin{array}{l}\text { Tendencia } \\
\text { social }\end{array}$ & $\begin{array}{l}\text { Quinta } \\
\text { promoción }\end{array}$ \\
\hline 15 & Abel Pacheco & $\begin{array}{l}\text { Exploración } \\
\text { del espacio subjetivo ... }\end{array}$ & $\begin{array}{l}\text { Social- } \\
\text { subjetivo... }\end{array}$ & $\begin{array}{l}\text { Tendencia } \\
\text { social }\end{array}$ & $\begin{array}{l}\text { Quinta } \\
\text { promoción }\end{array}$ \\
\hline 16 & Carmen Naranjo & $\begin{array}{l}\text { Exploración } \\
\text { del espacio subjetivo ... }\end{array}$ & $\begin{array}{l}\text { Social- } \\
\text { subjetivo... }\end{array}$ & $\begin{array}{l}\text { Tendencia } \\
\text { social }\end{array}$ & $\begin{array}{l}\text { Quinta } \\
\text { promoción }\end{array}$ \\
\hline 17 & José León Sánchez & $\begin{array}{l}\text { Exploración } \\
\text { del espacio subjetivo ... }\end{array}$ & $\begin{array}{l}\text { Social- } \\
\text { subjetivo... }\end{array}$ & $\begin{array}{l}\text { Tendencia } \\
\text { social }\end{array}$ & $\begin{array}{l}\text { Quinta } \\
\text { promoción }\end{array}$ \\
\hline 18 & Rima de Vallbona & $\begin{array}{l}\text { Exploración } \\
\text { del espacio subjetivo ... }\end{array}$ & $\begin{array}{l}\text { Social- } \\
\text { subjetivo... }\end{array}$ & $\begin{array}{l}\text { Tendencia } \\
\text { social }\end{array}$ & $\begin{array}{l}\text { Quinta } \\
\text { promoción }\end{array}$ \\
\hline 19 & Quince Duncan & $\begin{array}{l}\text { Exploración } \\
\text { del espacio subjetivo ... }\end{array}$ & $\begin{array}{l}\begin{array}{l}\text { Social- } \\
\text { subjetivo... }\end{array} \\
\end{array}$ & $\begin{array}{l}\text { Tendencia } \\
\text { social }\end{array}$ & $\begin{array}{l}\text { Quinta } \\
\text { promoción }\end{array}$ \\
\hline 20 & $\begin{array}{l}\text { Fernando Durán } \\
\text { Ayanegui }\end{array}$ & $\begin{array}{l}\text { Exploración } \\
\text { del espacio subjetivo ... }\end{array}$ & $\begin{array}{l}\text { Social- } \\
\text { subjetivo... }\end{array}$ & $\begin{array}{l}\text { Tendencia } \\
\text { social }\end{array}$ & $\begin{array}{l}\text { Quinta } \\
\text { promoción }\end{array}$ \\
\hline 21 & Alfonso Chase & $\begin{array}{l}\text { Exploración } \\
\text { del espacio subjetivo ... }\end{array}$ & $\begin{array}{l}\text { Social- } \\
\text { subjetivo... }\end{array}$ & $\begin{array}{l}\text { Tendencia } \\
\text { social }\end{array}$ & $\begin{array}{l}\text { Quinta } \\
\text { promoción }\end{array}$ \\
\hline 22 & Louis Ducoudray & $\begin{array}{l}\text { Exploración } \\
\text { del espacio subjetivo ... }\end{array}$ & $\begin{array}{l}\text { Social- } \\
\text { subjetivo... }\end{array}$ & $\begin{array}{l}\text { Tendencia } \\
\text { social }\end{array}$ & $\begin{array}{l}\text { Quinta } \\
\text { promoción }\end{array}$ \\
\hline 23 & Marco Retana & $\begin{array}{l}\text { Exploración } \\
\text { del espacio subjetivo ... }\end{array}$ & $\begin{array}{l}\text { Social- } \\
\text { subjetivo... }\end{array}$ & $\begin{array}{l}\text { Tendencia } \\
\text { social }\end{array}$ & $\begin{array}{l}\text { Quinta } \\
\text { promoción }\end{array}$ \\
\hline 24 & $\begin{array}{l}\text { Luis Bolaños } \\
\text { Ugalde }\end{array}$ & $\begin{array}{l}\text { Exploración } \\
\text { del espacio subjetivo ... }\end{array}$ & $\begin{array}{l}\text { Social- } \\
\text { subjetivo... }\end{array}$ & $\begin{array}{l}\text { Tendencia } \\
\text { social }\end{array}$ & $\begin{array}{l}\text { Quinta } \\
\text { promoción }\end{array}$ \\
\hline 25 & $\begin{array}{l}\text { José Ricardo } \\
\text { Chaves }\end{array}$ & $\begin{array}{l}\text { Deconstrucción de discursos } \\
\text { oficiales... }\end{array}$ & $\begin{array}{l}\text { La novela } \\
\text { histórica... }\end{array}$ & $\begin{array}{l}\text { Diversas } \\
\text { ópticas... }\end{array}$ & $\begin{array}{l}\text { Sexta } \\
\text { promoción }\end{array}$ \\
\hline 26 & Carlos Cortés & $\begin{array}{l}\text { Deconstrucción de discursos } \\
\text { oficiales }\end{array}$ & $\begin{array}{l}\text { La novela } \\
\text { histórica... }\end{array}$ & $\begin{array}{l}\text { Diversas } \\
\text { ópticas... }\end{array}$ & $\begin{array}{l}\text { Sexta } \\
\text { promoción }\end{array}$ \\
\hline 27 & Emilia Macaya & $\begin{array}{l}\text { Deconstrucción de discursos } \\
\text { oficiales ... }\end{array}$ & $\begin{array}{l}\text { La novela } \\
\text { histórica... }\end{array}$ & $\begin{array}{l}\text { Diversas } \\
\text { ópticas... }\end{array}$ & $\begin{array}{l}\text { Sexta } \\
\text { promoción }\end{array}$ \\
\hline 28 & Rosibel Morera & $\begin{array}{l}\text { Deconstrucción de discursos } \\
\text { oficiales... }\end{array}$ & $\begin{array}{l}\text { La novela } \\
\text { histórica... }\end{array}$ & $\begin{array}{l}\text { Diversas } \\
\text { ópticas... }\end{array}$ & $\begin{array}{l}\text { Sexta } \\
\text { promoción }\end{array}$ \\
\hline 29 & Uriel Quesada & $\begin{array}{l}\text { Deconstrucción de discursos } \\
\text { oficiales... }\end{array}$ & $\begin{array}{l}\text { La novela } \\
\text { histórica... }\end{array}$ & $\begin{array}{l}\text { Diversas } \\
\text { ópticas... }\end{array}$ & $\begin{array}{l}\text { Sexta } \\
\text { promoción }\end{array}$ \\
\hline 30 & Alfredo Aguilar & $\begin{array}{l}\text { Deconstrucción de discursos } \\
\text { oficiales... }\end{array}$ & $\begin{array}{l}\text { La novela } \\
\text { histórica... }\end{array}$ & $\begin{array}{l}\text { Diversas } \\
\text { ópticas... }\end{array}$ & $\begin{array}{l}\text { Sexta } \\
\text { promoción }\end{array}$ \\
\hline
\end{tabular}

Tal y como se puede apreciar en la tabla, los escritores seleccionados se clasificaron según cuatro rasgos diferentes. Vale la pena destacar que la gran mayoría de ellos se ubicó dentro de la cuarta, quinta y sexta generaciones de la narrativa costarricense (columna E y filas de la 6 a la 30), lo cual implicaría, como se verá más adelante, que 
se favoreció la traducción del cuento literario costarricense más contemporáneo producido sobre todo durante la segunda mitad del siglo $\mathrm{xx}$ - quedando muy relegadas las manifestaciones más tempranas.

Se debe aclarar en este punto que tanto los criterios de clasificación como la clasificación misma de los escritores traducidos se realizó principalmente a partir de la obra del estudioso de la literatura costarricense Álvaro Quesada Soto (1996, 2008). Se utilizó la obra de Margarita Rojas y Flora Ovares (1995) para contrastar la información.

TABLA 9

Formalización de los datos correspondientes a la dimensión estructural del corpus: el contenido paratextual

\begin{tabular}{|c|c|c|c|c|c|c|}
\hline & $\mathrm{A}$ & $\mathrm{B}$ & $\mathrm{C}$ & $\mathrm{D}$ & $\mathrm{E}$ & $\mathrm{F}$ \\
\hline & Antología & Año & Espacio de publicación & Tipo & Propósito & No. sistemas \\
\hline 1 & $\begin{array}{l}\text { Contemporary } \\
\text { Costa Rican } \\
\text { Literature in... } \\
\end{array}$ & 1975 & $\begin{array}{l}\text { De recepción (Goshen, } \\
\text { Indiana) }\end{array}$ & Escolar & $\begin{array}{l}\text { Presentar los textos } \\
\text { más característicos de } \\
\text { un... }\end{array}$ & Bilateral \\
\hline 2 & $\begin{array}{l}\text { Five Women } \\
\text { Writers of } \\
\text { Costa Rica } \\
\end{array}$ & 1978 & $\begin{array}{l}\text { De recepción (Beaumont, } \\
\text { Texas) }\end{array}$ & Crítica & $\begin{array}{l}\text { Revolucionar formas } \\
\text { de comportamiento... }\end{array}$ & Bilateral \\
\hline 3 & $\begin{array}{l}\text { The Spanish } \\
\text { American Short } \\
\text { Story }\end{array}$ & 1980 & $\begin{array}{l}\text { De recepción (Los Angeles } \\
\text { y Berkeley) }\end{array}$ & Escolar & $\begin{array}{l}\text { Presentar los textos } \\
\text { más característicos de } \\
\text { un... }\end{array}$ & Multilateral \\
\hline 4 & \begin{tabular}{|l|l} 
Fiction \\
International \\
\end{tabular} & 1986 & $\begin{array}{l}\text { De recepción (San Diego, } \\
\text { California) }\end{array}$ & Crítica & \begin{tabular}{|l} 
Revolucionar formas \\
de comportamiento...
\end{tabular} & Multilateral \\
\hline 5 & $\begin{array}{l}\text { Women's } \\
\text { Fiction from } \\
\text { Latin America } \\
\end{array}$ & 1988 & $\begin{array}{l}\text { De recepción (Detroit, } \\
\text { Michigan) }\end{array}$ & Escolar & $\begin{array}{l}\text { Presentar los textos } \\
\text { más característicos de } \\
\text { un... }\end{array}$ & Multilateral \\
\hline 6 & $\begin{array}{l}\text { Clamor of } \\
\text { Innocence }\end{array}$ & 1988 & $\begin{array}{l}\text { De recepción (San } \\
\text { Francisco, California) }\end{array}$ & Crítica & $\begin{array}{l}\text { Revolucionar o } \\
\text { estabilizar formas } \\
\text { de... }\end{array}$ & Multilateral \\
\hline 7 & $\begin{array}{l}\text { And We Sold } \\
\text { the Rain }\end{array}$ & $\begin{array}{l}1988- \\
1989\end{array}$ & $\begin{array}{l}\text { De recepción (Nueva } \\
\text { York) }\end{array}$ & Crítica & $\begin{array}{l}\text { Revolucionar formas } \\
\text { de comportamiento... }\end{array}$ & Multilateral \\
\hline 8 & $\begin{array}{l}\text { Short Stories by } \\
\text { Latin American } \\
\text { Women } \\
\end{array}$ & 1989 & $\begin{array}{l}\text { De recepción (Houston, } \\
\text { Texas) }\end{array}$ & Crítica & $\begin{array}{l}\text { Revolucionar formas } \\
\text { de comportamiento... }\end{array}$ & Multilateral \\
\hline 9 & $\begin{array}{l}\text { Landscapes of a } \\
\text { New Land }\end{array}$ & 1989 & $\begin{array}{l}\text { De recepción (Nueva } \\
\text { York) }\end{array}$ & Crítica & $\begin{array}{l}\text { Revolucionar formas } \\
\text { de comportamiento... }\end{array}$ & Multilateral \\
\hline 10 & $\begin{array}{l}\text { Scents of Wood } \\
\text { and Silence }\end{array}$ & 1991 & De recepción (Pittsburgh) & Crítica & $\begin{array}{l}\text { Revolucionar formas } \\
\text { de comportamiento... }\end{array}$ & Multilateral \\
\hline 11 & $\begin{array}{l}\text { When New } \\
\text { Flowers } \\
\text { Bloomed } \\
\end{array}$ & 1991 & De recepción (Pittsburgh) & Crítica & $\begin{array}{l}\text { Revolucionar o } \\
\text { estabilizar formas } \\
\text { de... }\end{array}$ & Multilateral \\
\hline 12 & Global cultures & 1994 & $\begin{array}{l}\text { De recepción } \\
\text { (Connecticut) }\end{array}$ & Crítica & $\begin{array}{l}\text { Revolucionar formas } \\
\text { de comportamiento... }\end{array}$ & Multilateral \\
\hline 13 & $\begin{array}{l}\text { Costa Rica: a } \\
\text { traveler's } \\
\text { literary } \\
\text { companion } \\
\end{array}$ & 1994 & $\begin{array}{l}\text { De recepción (Berkeley, } \\
\text { California) }\end{array}$ & $\begin{array}{l}\text { Comer_ } \\
\text { cial }\end{array}$ & $\begin{array}{l}\text { Satisfacer necesidades } \\
\text { del usuario... }\end{array}$ & Bilateral \\
\hline 14 & $\begin{array}{l}\text { Contemporary } \\
\text { Short Stories } \\
\text { from... } \\
\end{array}$ & 1994 & $\begin{array}{l}\text { De recepción (Austin, } \\
\text { Texas) }\end{array}$ & Escolar & $\begin{array}{l}\text { Presentar los textos } \\
\text { más característicos de } \\
\text { un... }\end{array}$ & Multilateral \\
\hline 15 & $\begin{array}{l}\text { Out of the } \\
\text { Mirror Garden }\end{array}$ & 1996 & $\begin{array}{l}\text { De recepción (Nueva } \\
\text { York) }\end{array}$ & Crítica & $\begin{array}{l}\text { Revolucionar formas } \\
\text { de comportamiento... }\end{array}$ & Multilateral \\
\hline 16 & $\begin{array}{l}\text { Sudden Fiction } \\
\text { Latino }\end{array}$ & 2010 & $\begin{array}{l}\text { De recepción (Nueva York } \\
\text { y Londres) }\end{array}$ & Crítica & $\begin{array}{l}\text { Revolucionar formas } \\
\text { de comportamiento... }\end{array}$ & Multilateral \\
\hline
\end{tabular}


La tabla anterior deja ver desde ya rasgos muy característicos de las antologías estudiadas. Destacan entre ellos por su homogeneidad -aunque no sorprende- el hecho de que todas las publicaciones se produjeron dentro del polo de recepción, así como la naturaleza multilateral de la mayoría de los volúmenes, esto es, el que en ellas se hayan incluido traducciones provenientes de múltiples polos de partida (y no solo de Costa Rica). Evidente es pues que los intereses detrás de la producción de las antologías iban más allá del ámbito literario costarricense.

Como punto final de este apartado se debe recordar el hecho de que de la misma manera en que se construyeron las dos tablas que han servido de ejemplo, se construyeron tablas similares para conjuntar y configurar las restantes dimensiones del corpus estudiado.

\subsection{Los resultados}

Conjuntar la información relativa a cada uno de los aspectos estudiados sobre el corpus de antologías permitió la síntesis de los datos en cada una de las tablas mencionadas en el apartado anterior. De tal manera, fue posible extraer una serie de patrones reconocibles en términos numéricos o valores porcentuales relativos a cada aspecto. Tales valores permiten identificar tendencias en el corpus que resultaron útiles para la posterior interpretación de la realidad estudiada.

Retomando los casos de las dimensiones convencional y estructural que sirvieron de ejemplo en el epígrafe anterior, se presentan ahora -también a manera de ejemplolos resultados del análisis de los aspectos relacionados con los escritores traducidos y con el contenido paratextual del corpus. Las tablas 10 y 11, que se muestran a continuación, son el producto resultante de sintetizar la información inscrita en la tabla 8.

Como ya se advertía en párrafos anteriores, llama la atención la pertenencia de una amplia mayoría $(82,66 \%)$ de los escritores seleccionados a las tres generaciones más contemporáneas de la narrativa costarricense. De la misma manera, destaca el interés en asuntos de corte social como componente predominante entre las filiaciones ideológicas, poéticas y estéticas asociadas a los escritores.

TABLA 10

Tendencias dominantes 6 entre los escritores traducidos en cuanto a sus filiaciones ideológicas y a la función poética que cumplen sus escritos

\begin{tabular}{|l|l|l|}
\hline Tendencia & Filiación ideológica & Función poética (de los escritos) \\
\hline $\mathbf{4 6 , 6 6 \%}$ & Tendencia social & $\begin{array}{l}\text { 1) Explorar el espacio subjetivo así como nuevas formas y } \\
\text { contenidos, 2) reformular los modelos estético-literarios } \\
\text { anteriores y 3) reestructurar el orden social }\end{array}$ \\
\hline $\mathbf{2 0 , 0 0 \%}$ & $\begin{array}{l}\text { - Diversas ópticas } \\
\text { - Realismo social }\end{array}$ & $\begin{array}{l}\text { 1) Deconstruir los discursos oficiales y 2) ofrecer una } \\
\text { reinterpretación crítica de la historia oficial }\end{array}$ \\
\hline $\mathbf{1 0 , 0 0 \%}$ & $\begin{array}{l}\text { - Socialismo } \\
\text { - Comunismo }\end{array}$ & $\begin{array}{l}\text { 1) Explorar, descubrir y redefinir desde lo subjetivo y } \\
\text { discursivo y 2) reposicionar al individuo con respecto al } \\
\text { orden social tradicional }\end{array}$ \\
\hline
\end{tabular}


TABLA 11

Tendencias entre los escritores traducidos en cuanto al núcleo generacional al que pertenecen y a sus filiaciones estéticas

\begin{tabular}{|c|c|c|}
\hline & A & $\mathrm{B}$ \\
\hline & Núcleo generacional & Filiación estética \\
\hline 1 & $46,66 \%$ quinta promoción & $\begin{array}{l}46,66 \% \text { social-subjetivo, historicismo, literatura fantástica y } \\
\text { de intención lúdica, «vanguardista» }\end{array}$ \\
\hline 2 & $20,00 \%$ sexta promoción & $\begin{array}{l}20,00 \% \text { novela histórica, realismo tradicional, realismo } \\
\text { fantástico, «vanguardista» }\end{array}$ \\
\hline 3 & $16,66 \%$ cuarta promoción & $10,00 \%$ lo psicológico, subjetivismo o vanguardismo \\
\hline 4 & $6,66 \%$ segunda promoción & $6,66 \%$ lo social, lo agrario, el realismo \\
\hline 5 & $6,66 \%$ tercera promoción & $\begin{array}{l}6,66 \% \text { naturalismo, realismo, decadentismo, simbolismo, } \\
\text { modernismo, cosmopolitismo }\end{array}$ \\
\hline 6 & $3,33 \%$ primera promoción & $\begin{array}{l}3,33 \% \text { mezcla de realismo costumbrista con impresionismo; } \\
\text { vanguardismo }\end{array}$ \\
\hline 7 & & $3,33 \%$ vanguardismo \\
\hline 8 & & $3,33 \%$ costumbrismo \\
\hline
\end{tabular}

A continuación se presentan -por medio de las siguientes tablas- los resultados extraídos a partir de los datos consignados en la tabla 9.

TABLA 12

Tendencias en cuanto al momento de publicación, espacio de publicación y número de sistemas incluidos en las antologías

\begin{tabular}{|l|c|c|c|}
\hline & A & B & \multicolumn{1}{c|}{ C } \\
\hline & Momento de publicación & Espacio de publicación & \multicolumn{1}{c|}{ Número de sistemas } \\
\hline 1 & $12,50 \%$ durante la década de 1970 & $100 \%$ de recepción & $81,25 \%$ multilaterales \\
\hline 2 & $37,50 \%$ durante la década de 1980 & & $18,75 \%$ bilateral \\
\hline 3 & $43,75 \%$ a partir de 1991 & & \\
\hline
\end{tabular}

\section{TABLA 13}

Tendencias en cuanto al tipo de antologías estudiadas

\section{Tipo de antología}

$56,25 \%$ crítica (100,00\% obra literaria, $44,44 \%$ poético, $22,22 \%$ social, $22,22 \%$ sociopolítico, $11,11 \%$ político, $11,11 \%$ cultural, $11,11 \%$ sociocultural)

$25,00 \%$ escolar (libro de texto)

$12,50 \%$ principalmente crítica (poético, obra literaria) y escolar (libro de texto) de manera secundaria

$6,25 \%$ comercial (producto de entretenimiento u ocio)

Los datos en la tabla 9 también permitieron extraer resultados en cuanto al propósito que tenían las antologías con respecto al polo de recepción ${ }^{7}$. En tal sentido fue posible distinguir dos tendencias principales: la primera muestra que en exactamente la mitad de las antologías lo que se buscaba era estabilizar o por el contrario revolucionar -según fuera el caso- las formas de comportamiento más usuales o las perspectivas convencionales del polo de recepción con respecto al polo de partida. La segunda indica que en un cuarto de los volúmenes lo que se pretendía era presentar al lector los textos más característicos de un periodo o región, así como los más úti- 
les para el trabajo académico. Para finalizar, los resultados revelaron cuatro propósitos más: 1) satisfacer las necesidades del usuario/consumidor, 2) revolucionar las formas de comportamiento más usuales o las perspectivas convencionales, y presentar los textos más característicos de un periodo, grupo o región, 3) revolucionar las formas de comportamiento más usuales o las perspectivas convencionales (con respecto a la producción literaria de las mujeres escritoras centroamericanas y a las prácticas editoriales a las que se encontraban sujetas en Estados Unidos) y presentar textos útiles para el trabajo académico, y 4) revolucionar las formas de comportamiento más usuales o las perspectivas convencionales (con respecto a la visión histórico-política sesgada y manipulada que se tenía de Centroamérica dentro de los Estados Unidos, presentando una imagen más amplia y menos prejuiciada). Cada uno de los cuatro propósitos anteriores da cuenta de una única publicación.

Los resultados consignados en las tablas que forman parte de este epígrafe, así como las producidas a partir de los datos relativos al resto de aspectos estudiados véase $\$ 2.2$. Los aspectos estudiados- conforman la base empírica que permitió generar las secciones de recapitulación y conclusiones.

\section{Recapitulación}

Los resultados, que se presentan de seguido, se han dispuesto en tres secciones: los relacionados con la producción de las antologías estudiadas, los relativos al proceso de selección de escritores y textos traducidos, y los que tienen que ver con la imagen que las traducciones proyectan del cuento literario costarricense.

\subsection{En cuanto a la producción de las antologías y de las traducciones}

En este sentido se debe destacar que el proceso de producción habría dependido por completo del polo de recepción. Tal hecho se debería principalmente a que todas las antologías estudiadas se publicaron en el contexto meta, a que las editoriales que las publican estaban todas afincadas en aquel espacio y a que alrededor del $70 \%$ de quienes protagonizaron aquel proceso procedían de dicho entorno.

En cuanto a su aparición, tal parece que se relaciona, primero, con la relevancia (sociopolítica, académica y literaria) que ciertos colectivos minoritarios cobran en momentos históricos específicos dentro del polo de recepción -por ejemplo, la importancia que cobra el colectivo de mujeres dentro del ámbito académico-universitario estadounidense gracias a la proliferación de los programas de estudios de la mujer durante la década de 1970 y su consolidación durante el siguiente decenio; un caso similar lo representa la visibilidad que adquieren diversos colectivos minoritarios debido a la expansión de los llamados estudios culturales en la academia estadounidense durante las décadas de 1980 y 1990. A estos hechos hay que sumarles, claro, el impacto que al respecto tuvieron los movimientos de derechos civiles y feministas acaecidos durante las décadas de 1950, 1960 y 1970-, segundo, con la relevancia (geopolítica y comercial) que cobra el polo de partida dentro del polo de recepción -geopolítica sobre todo a partir de los conflictos armados en Centroamérica y del intervencionismo estadounidense durante la segunda mitad del siglo pasado en el área latinoamericana en general; comercial principalmente a partir del fin de la guerra fría y el posterior auge de los tratados comerciales entre Estados Unidos y diferentes 
regiones o países de Latinoamérica- y, tercero, con la relevancia (política y lingüística) que parece cobrar el colectivo latino e hispanoamericano también dentro del polo de recepción -durante la última década del siglo $\mathrm{xx}$, Estados Unidos experimenta la mayor oleada de inmigrantes de su historia (Fix y Passel 2001), gran parte de los cuales provenía de Hispanoamérica: la cantidad de inmigrantes de origen mexicano, por poner un ejemplo, había ido en aumento paulatino desde la década de 1980 hasta alcanzar los más de 400 mil al año durante el siguiente decenio (Gaspar Olvera 2012: 106). En la misma línea, también parece muy significativo el hecho de que, durante la primera campaña presidencial de George W. Bush, el candidato republicano apareció en televisión nacional interpelando al colectivo hispanohablante residente en los Estados Unidos en español-; los tres hechos resultan constatables al observar el contexto histórico-social en que se produjo la mayoría de las antologías estudiadas.

Por otro lado, parece evidente que la producción de las antologías estudiadas toma lugar mayoritariamente dentro de los ámbitos literario, editorial o académico, de carácter universitario, minoritario o independiente; todos ámbitos para los cuales los colectivos recién referidos resultaban relevantes. De manera similar, la gran mayoría de los actores que dirigen tal proceso no tienen a la traducción como su campo de acción, sino que se encuentran vinculados sobre todo a actividades de índole literaria, editorial o académica.

En cuanto a su propósito, la producción de las antologías en cuestión ha estado dirigida a suplir sobre todo las demandas de un lector no especializado, que se interesa en los colectivos o áreas geopolíticas y culturales representadas -por el contenido de las antologías- en términos literarios y sociopolíticos.

En el caso específico de las traducciones de cuento costarricense, en su mayoría su aparición se vincula al hecho de que históricamente la tradición literaria costarricense se ha visualizado (desde el exterior) siempre como asociada al área centroamericana y latinoamericana, tanto en términos geopolíticos como lingüísticos y literarios.

Por otra parte, los planteamientos recién expuestos parecen revelar no solo el conjunto de componentes propios del polo de recepción que intervinieron en la producción de las antologías analizadas, sino además la manera en que tales componentes interactuaron entre sí y con su entorno (en términos sociopolíticos, socioculturales, sociolingüísticos e históricos) para generar las posibilidades de publicación respectivas. Se evidencia así lo provechoso que puede resultar el estudio de las antologías de traducción para poner de manifiesto el funcionamiento interno de los polos de recepción (Gallego Roca 1994: 249).

\subsection{En cuanto a la selección de los escritores y textos que fueron traducidos}

Al igual que ocurriera con el proceso de producción y prácticamente por las mismas razones, la selección de escritores y textos traducidos dependió por completo del polo de recepción. Tal selección se relaciona con la aparición o existencia de espacios dentro del polo de recepción de tipo universitario, minoritario o de ruptura, tendentes a lo social, femenino, étnico, multicultural o político, que habrían funcionado como espacios de acogida y promoción para las literaturas minoritarias extranjeras. De manera complementaria, los editores (protagonistas del proceso en cuestión) habrían seleccionado en función de una audiencia meta no masiva y predeterminada, 
que tendría intereses principalmente sociales, políticos y literarios, así como académicos, aunque estos últimos solo de manera secundaria.

En otro orden de cosas y haciendo eco de lo postulado por Toury (1995) en cuanto a las políticas de traducción, el proceso de selección se habría asegurado de que el material por traducir encajara con la imagen previa que se habría tenido del polo de partida dentro del polo de recepción. En este sentido, quienes protagonizan tal proceso, posiblemente de manera inconsciente, habrían tomado como punto de partida una imagen predeterminada del entorno de origen y de su literatura. Como resultado, las filiaciones estéticas, poéticas e incluso ideológicas de aquellos y aquello que se seleccionó habrían tenido que ajustarse de entrada a tal imagen. Ya de manera más específica, la selección de material habría dependido también de lo adecuado o de la posibilidad de que se adecuase a las antologías en que se incluiría, en tanto proyectos temáticos, ideológicos y poéticos en sí mismos.

En cuanto a los escritores traducidos, su selección parece haber estado vinculada en principio al capital simbólico o grado de visibilidad que tenían dentro del polo de partida al momento de ser seleccionados. Su notoriedad local les habría hecho más visibles ante aquellos ojos extranjeros que se asomasen al ámbito costarricense en busca de autores por traducir. Por otra parte, y en concordancia con lo planteado por Odber de Baubeta (2012: 72-73), la traducción de tales escritores, su inclusión en las antologías y su posterior incorporación (en términos relativos) al panorama literario de recepción habría redundado en el aumentado de aquel capital simbólico y les habría hecho subir aun más o afianzado en el escalafón literario, al menos en lo que concierne al polo de partida.

En ambos casos (escritores y material) la selección se habría visto condicionada por un criterio de contemporaneidad. El hecho de que $70 \%$ del material literario que llegó a seleccionarse hubiese sido publicado a partir de la década de 1960 sustenta tal afirmación. Dicha situación se relacionaría con el interés -sociopolítico, geopolítico, político y literario- por la situación contemporánea del polo de partida que habrían tenido los productores y diversos sectores del propio polo de recepción. Al respecto, no está de más mencionar que la creación de la Latin American Studies Association en 1966 parece ser un hecho ilustrativo de aquel interés que despertaba Latinoamérica en ciertos ámbitos estadounidenses durante la segunda mitad del siglo pasado.

Además de lo recién apuntado, la selección de escritores y cuentos costarricenses por traducir dependió en su momento de un requisito inicial: su pertenencia a un espacio lingüístico, cultural y geopolítico más amplio, que resultaba muy atractivo a ciertos sectores del polo de recepción -más interesados en la literatura latinoamericana, hispanoamericana o centroamericana (como representativa de colectivos que les eran más visibles e interesantes) que específicamente en la costarricense-. En esa misma línea, no se debe olvidar, además, que aquel espacio (centroamericano) fue objeto directo de una política intervencionista especialmente agresiva por parte de los Estados Unidos durante la segunda mitad del siglo xx. Tal política tendía a agrupar a las naciones centroamericanas bajo una misma óptica y habría generado, en el polo de recepción, una imagen homogénea de los países que integraban la región. Así, es probable que, a los ojos de los sectores interesados dentro del polo de recepción, el que Costa Rica fuese parte de aquel espacio habría borrado en buena medida sus singularidades, incluidas las de su producción literaria, hasta volverla por extensión casi indistinguible del resto del espacio centroamericano, sin importar que su 
realidad o manifestaciones literarias particulares pudieran diferir. Estos hechos habrían propiciado, de manera indirecta, que el interés por traducir literatura costarricense pudiera haber sido hasta cierto punto un efecto del interés y acciones del polo de recepción sobre las regiones centroamericana, hispanoamericana o latinoamericana. Esta idea parece evidente si se toma en cuenta que más del $80 \%$ de las antologías se catalogaron como multilaterales: en ellas se incluyó literatura que provenía de múltiples espacios o países centroamericanos, hispanoamericanos o latinoamericanos además del costarricense.

\subsection{En cuanto a la imagen que el paratexto de las antologías proyecta del cuento literario costarricense}

La imagen que generan las antologías presenta al cuento literario costarricense como una tradición fundamentalmente asociada a corrientes literarias de carácter regional, ya que en la mayoría de los casos se le muestra como un componente más dentro de tradiciones o manifestaciones más amplias: la literatura latinoamericana, hispanoamericana o centroamericana, de corte social o femenino. Se trataría también de una literatura relativamente joven, con poco más de medio siglo de vida. Esto ya que, tal y como se ha hecho constar con anterioridad, se seleccionaron escritores y cuentos publicados dentro del polo de partida (Costa Rica) sobre todo durante la segunda mitad del siglo pasado. Asimismo, dada la selección, sería una literatura predominantemente centrada en diversos grupos y problemas sociales, y de corte femenino, político, social, realista y sociopolítico. En la misma línea pero ahora en cuanto a sus temas, sería una corriente comprometida con los contenidos de corte sociocultural: principalmente la problemática social, lo cotidiano, la sociedad, la cuestión femenina, lo cultural y los conflictos raciales, étnicos e idiosincrásicos.

Las ideas recién expuestas implican que las antologías y sus paratextos generan o proyectan una imagen sesgada del cuento literario costarricense. La selección realizada no refleja el desarrollo histórico de la tradición literaria de origen -se han dejado de lado sobre todo sus primeros representantes, manifestaciones, temáticas y preocupaciones-. Tal situación habría tenido su origen en el hecho de que los propósitos de quienes se encargaron de los procesos de producción y selección asociados a las antologías no son en términos estrictos académicos o historiográficos, sino principalmente literarios y editoriales, y se focalizan en momentos, grupos y situaciones específicas del polo de partida que interesan al polo de recepción. Por consiguiente, aunque las antologías de traducción estudiadas en efecto pudieron funcionar como medios de transmisión de la producción literaria de un país (Göske 1991: 35-36), han sido medios parcializados, esto es, han favorecido solo ciertas manifestaciones, sin preocuparse por transmitir una imagen más representativa de la tradición literaria que difunden.

Al menos en lo concerniente al estudio realizado, la situación recién referida parece ser ilustrativa de la manera en que un conjunto de antologías y sus contenidos incidirían en la imagen que de una literatura dada e incluso de su entorno sociocultural e histórico puede llegar a fabricarse dentro de un polo de recepción específico -hecho al que ya se hacía referencia en apartados previos (véase $\$$ Introducción) al discutirse las funciones potenciales de las antologías de traducción-. Tal situación revela, además, la función que pueden llegar a cumplir las antologías de traducción como elementos estructuradores del medio cultural de recepción (Essmann y Frank 1991: 66,68), esto 
al incorporar, transformar o, como parece haber ocurrido con el caso bajo estudio, afianzar una cierta visión del entorno de partida dentro de la cultura meta.

\section{Conclusiones}

A partir de los resultados recién expuestos ha sido posible plantear una serie de principios por medio de los cuales se intenta ahora describir la naturaleza de la traducción de literaturas periféricas en entornos dominantes. Así, en cuanto a la mecánica que rige la actividad en cuestión, se pueden postular dos ideas principales. Primero, que vendría a ser una actividad usualmente autónoma con respecto del polo de partida y a la vez dependiente del polo de recepción y, segundo, que sus dimensiones referencial y estructural están condicionadas de manera directa por su dimensión intencional, e indirectamente por sus dimensiones contextual y convencional -esto último en concordancia con lo que postulan sobre todo las corrientes polisistémicas y funcionalistas en traducción-.

Por otro lado, la interpretación de los resultados permite plantear de forma preliminar que su aparición en entornos literarios dominantes dependería en principio de al menos cinco factores:

1) la existencia o aparición dentro del polo de recepción de espacios minoritarios;

2) los espacios y ambientes universitarios, pero sobre todo editoriales independientes, cuya función sería determinante en tanto propulsores y ejecutores de las diferentes iniciativas de publicación/traducción;

3) la relevancia histórica que alcance el polo de partida dentro de tales espacios y ambientes;

4) la existencia de un lector no masivo, interesado en el polo de partida en términos literarios, pero sobre todo sociopolíticos; y

5) la existencia de material original que se adecue a las expectativas de productores $y$ lectores meta.

Así pues y en consonancia con lo planteado en otros momentos (Siebenmann 1991; Alvstad 2012; Vargas Gómez 2012, 2015; Bielsa 2013; Franco Aixelá y Vargas Gómez 2012; Galvin 2014) se concluye que la traducción de literaturas periféricas en entornos dominantes se caracterizaría por ser una actividad que:

1) refleja -tanto en la selección de materiales por traducir como en la producción de traducciones determinadas- los intereses de los actores que la protagonizan, así como la interacción de tales actores con el polo de recepción;

2) no es un medio de difusión democrático como tampoco un puente neutral entre culturas, esto ya que no necesariamente implica ni un intercambio equitativo ni una verdadera interacción equilibrada entre los polos involucrados (compárese con Franco Aixelá y Vargas Gómez 2012);

3) no es una actividad o sistema primario autogobernado, sino uno secundario que se adecua a normas prefijadas en otros sistemas (primarios) del polo de recepción -como el literario, el editorial, el sociopolítico o el económico-; es entonces una actividad de carácter subsidiario e instrumental, sin capacidad aparente para regirse a sí misma y que, por el contrario, se encuentra al servicio de otras actividades cuyos objetivos e intereses la condicionan;

4) genera, dentro del polo de recepción, imágenes sesgadas de la literatura y del polo de partida que concuerdan con imágenes preestablecidas o con intereses particulares; y 
5) al encontrarse condicionada por los sistemas primarios a los cuales sirve en determinados momentos y espacios, será precisamente en su interacción con tales sistemas en donde debe buscarse el origen de los comportamientos traductores que lleguen a observarse. La modificación de tales comportamientos dependerá de la evolución de los sistemas primarios a los cuales se asocia la actividad traductora y a los que sirve.

Solo resta señalar que la delimitación de los principios recién demarcados a partir del estudio realizado parece respaldar las ideas antes planteadas (véase $₫$ Introducción) sobre la utilidad de las antologías de traducción como un instrumento por medio del cual intentar comprender el fenómeno de la traducción (de literaturas periféricas) y las fuerzas que le gobiernan.

\section{NOTAS}

1. Entiéndase en este caso por literaturas periféricas todas aquellas que tradicionalmente no han entrado en el canon literario occidental y que han quedado, por lo tanto, al margen de sus corrientes y circuitos editoriales. Desde tal punto de vista, las literaturas periféricas han resultado en términos históricos muy poco o nada difundidas, traducidas, leídas o estudiadas más allá de sus propios ámbitos de producción, tal y como ha ocurrido, para lo que concierne, con la literatura costarricense. Por otro lado, debe comprenderse un entorno lingüístico hegemónico como aquel espacio geopolítico que se haya posicionado como referente geopolítico, comercial, económico y cultural en el medio internacional, y dentro del cual se hace uso mayoritario de una lengua que, de manera similar, también haya cobrado primacía en el escenario mundial como lengua vehicular (lingua franca) entre hablantes de diferentes idiomas.

2. Aunque no refiere estrictamente a obras literarias, resulta hasta cierto punto ilustrativo para el caso que al realizar una búsqueda básica en el catálogo del OCLC WorldCat, al 18 de enero de 2017 se registran 939 referencias a libros bajo el criterio de búsqueda «literature of Costa Rica», mientras que se obtienen 984 para «literature of El Salvador», 1030 para «literature of Bolivia», 1083 para «literature of Panama», 1234 para «literature of Uruguay», 1263 para «literature of Ecuador», 1430 para «literature of Guatemala», 1595 para «literature of Haiti», 226 para «literature of Venezuela», 2416 para «literature of Jamaica», 2995 para «literature of Puerto Rico», 3355 para «literature of Colombia», 3657 para «literature of Peru», 3745 para «literature of Chile», 3985 para «literature of Cuba», 7659 para «literature of Argentina» y 27550 para «literature of Mexico».

3. Como ejemplo, según cifras generales obtenidas por medio del Index translationum de la Unesco (<http://www.unesco.org/xtrans/>, consultado por última vez el 25 de agosto de 2014), entre 1988 y 1996 -periodo durante el cual se publicó la mayoría de las antologías estudiadas- la literatura costarricense solo llega a representar el 6,8\% del total de la literatura centroamericana que se traduce e incorpora al entorno estadounidense y apenas el $0,3 \%$ del total de traducciones literarias del español al inglés que se publicaron entre aquellos años.

4. Para una exposición detallada del concepto de paratexto, véase la obra de Gérard Genette (1987/1997).

5. En conjunto las 16 antologías contenían las traducciones de 90 cuentos literarios, escritos originalmente en español por una treintena de escritores costarricenses: en 7 de ellas se incluyó una única traducción, en 2 se publicaron 2 traducciones respectivamente, en 2 más se publicaron 3 traducciones, en una 6 traducciones, 11 traducciones en otra, en la siguiente se encontraron 12 traducciones, en una más 18 traducciones y 26 en la última.

6. Se aclara que se identificaron otras tendencias; no obstante, resultan porcentualmente irrelevantes. Es por tal razón que no se han incluido ahora.

7. La información relativa al propósito de las antologías con respecto al polo de recepción se ha extraído de los aparatos paratextuales de los textos estudiados. Por lo tanto, las categorías señaladas en tal sentido corresponden a la síntesis de los propósitos individuales de cada volumen, usualmente declarados en el paratexto por aquellos -editores o antólogos- que tuvieron a su cargo la producción de las antologías según lo que se pretendía alcanzar con su publicación. Así pues, el término «propósito» en este caso debe remitir de manera exclusiva a la intención que ha quedado manifiesta en el paratexto publicado o que se puede inferir del mismo sin lugar a dudas, y que por lo tanto influye en la configuración o imagen que de los contenidos de cada texto pueda hacerse el lector. 
Quedan excluidos entonces los posibles propósitos de diferentes agentes que pudieran haber estado involucrados en el proceso de producción de las antologías estudiadas (los autores, los agentes literarios o editoriales, los traductores e incluso las editoriales) así como los de quienes podrían intervenir en momentos posteriores a la producción de las antologías (los lectores, por ejemplo).

\section{REFERENCIAS BIBLIOGRÁFICAS}

Alvstad, Cecilia (2012): Anthologizing Latin American Literature: Swedish Translative ReImaginings of Latin America 1954-1998 and Links to Travel Writing. ANGLO SAXONICA. III(3):39-68.

Bielsa, Esperança (2013): Translation and the International Circulation of Literature. A Comparative Analysis of the Reception of Roberto Bolaño's Work in Spanish and English. The Translator. 2(19):157-182.

Bourdieu, Pierre (1977): Outline of a Theory of Practice. Cambridge: Cambridge University Press.

Bourdieu, Pierre (1991): Language and Symbolic Power. Cambridge: Polity Press.

D'Hulst, Lieven (1995): Anthologies of French Medieval Literature (1756-1816): Between Translation and Editing. In: Harald KitTeL, ed. International Anthologies of Literature in Translation. Berlín: Erich Schmidt, 1-14.

Enríquez Aranda, María Mercedes (2004): Análisis externo de las antologías de traducción españolas del romanticismo poético inglés (1915-2002). Trans. 8:61-74.

Essmann, Helga y Frank, Armin Paul (1991): Translation Anthologies: An Invitation to the Curious and a Case Study. Target. 3(1):65-90.

FIX, Michael E. y PAssel, Jeffrey S. (2001): U.S. Immigration at the Beginning of the 21st Century. Urban Institute. Consultado el 17 de enero de 2017, <http://www.urban.org/research/ publication/us-immigration-beginning-21st-century $>$.

Franco Aixelá, Javier y Vargas Gómez, Francisco (2012): Un cuestionamiento al mito del puente cultural: la traducción como embudo y el ejemplo de la poesía costarricense. Letras. 2(52):119-134.

Gallego Roca, Miguel (1994): La ordenación del caos: poesía traducida y antologada. Sendebar. 5:249-253.

Galvin, Rachel (2014): Poetic Innovation and Appropriative Translation in the Americas. In: Sandra Bermann y Catherine Porter, eds. A Companion to Translation Studies. Malden/ Oxford: Wiley-Blackwell, 361-374.

Gaspar Olvera, Selene (2012): Migración México-Estados Unidos en cifras (1990-2011). Migración y desarrollo. 10(18):101-138.

Genette, Gérard (1987/1997): Paratexts. Thresholds of Interpretation. (Translated by Jane E. LEWIN and Richard MaCksey) Cambridge: Cambridge University Press.

Göske, Daniel (1990): 'Kindred Spirits?' The Question of America's Literary Independence as Reflected in Early German Anthologies of Poetry. Amerikastudien / American Studies. $1(35): 35-51$.

Kamenish, Paula y Zabic, Snezana (2006): A Survey of Bosnian, Croatian, and Serbian Poetry in English Translation in the U.S. and Canada. CLCWeb: Comparative Literature and Culture. 8(3):9 p. Consultado el 25 de enero de 2017, <https://docs.lib.purdue.edu/clcweb/ vol8/iss $3 / 5 />$.

Linn, Stella (2006): Trends in the translation of a minority language. The case of Dutch. In: Anthony Pym, Miriam Shlesinger y Zuzana Jettmarová, eds. Sociocultural Aspects of Translating and Interpreting. Amsterdam/Filadelfia: John Benjamins, 27-39.

Odber de Baubeta, Patricia Anne (2012): The Intersection of Translation Studies and Anthology Studies. ANGLO SAXONICA. III(3):69-84.

Ozвот, Martina (2011): Dwarfs in Giants' Lands: Some Observations on Translating Minor Literatures into High-Impact Cultures - The Case of Slovenian Literature in Italy. Meta. 3(56):511-525. 
PopA, Ioana (2006): Translation channels. A primer on politicized transfer. Target. 2(18):205-228. Pym, Anthony (2006): On the Social and Cultural in Translation Studies [introduction]. In: Anthony Pym, Miriam Shlesinger y Zuzana Jettmarová, eds. Sociocultural Aspects of Translating and Interpreting. Amsterdam/Filadelfia: John Benjamins, 1-25.

Quesada Sото, Álvaro (1996): Antología del relato costarricense (1890-1930). San José: Editorial de la Universidad de Costa Rica.

Quesada Soto, Álvaro (2008): Breve historia de la literatura costarricense. San José: Editorial Costa Rica.

Rojas, Margarita y Ovares, Flora (1995): 100 años de literatura costarricense. San José: Farben/ Norma.

SAMPson, Fiona (2004): Publishing poetry in translation in the UK: the Slovak experience. The Public. 4(11):79-90.

SAntos, Rosario, ed. (1988): And We Sold the Rain: Contemporary Fiction from Central America. Nueva York: Four Walls Eight Windows.

Siebenmann, Gustav (1991): La literatura latinoamericana en los países de habla alemana. Revista hispánica moderna. 1(44):124-237.

Thompson, John B. (1990): Ideology and Modern Culture. Cambridge: Polity Press.

Toury, Gideon (1995): Descriptive Translation Studies - and beyond. Amsterdam/Filadelfia: John Benjamins.

VArgas Gómez, Francisco (2012): Avatares de la poesía costarricense traducida durante el siglo $X X$. Tesis de doctorado no publicada. Alicante: Universidad de Alicante.

Vargas Gómez, Francisco (2015): Mímesis y adecuación en la traducción de una literatura periférica: la poesía de Costa Rica. Hermeneus. Revista de Traducción e Interpretación. 17:253-278.

Wolf, Michaela y Fukari, Alexandra, eds. (2007): Constructing a Sociology of Translation. Amsterdam/Filadelfia: John Benjamins. 